\title{
(6) OPEN ACCESS \\ Effect of ski geometry on aggressive ski behaviour and visual aesthetics: equipment designed to reduce risk of severe traumatic knee injuries in alpine giant slalom ski racing
}

\author{
Josef Kröll, ${ }^{1}$ Jörg Spörri, ${ }^{1}$ Matthias Gilgien, ${ }^{2}$ Hermann Schwameder, ${ }^{1}$ Erich Müller ${ }^{1}$
}

${ }^{1}$ Department of Sport Science and Kinesiology, University of Salzburg, Hallein-Rif, Austria ${ }^{2}$ Department of Physical Performance, Norwegian School of Sport Sciences, Oslo, Norway

\section{Correspondence to} Dr Josef Kröll, Department of Sport Science and Kinesiology, University of Salzburg, Hallein-Rif 5400, Austria; josef.kroell@sbg.ac.at

Accepted 19 October 2015 Published Online First 24 November 2015
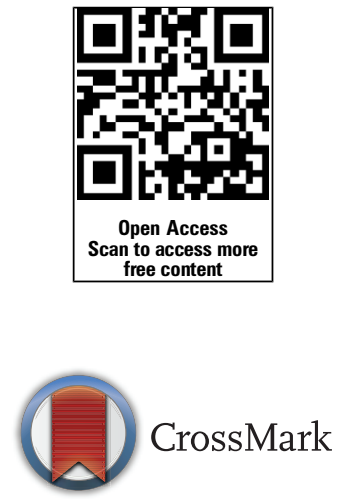

To cite: Kröll J, Spörri J, Gilgien $\mathrm{M}$, et al. Br J Sports Med 2016;50:20-25.
ABSTRACT

Background/Aim Aggressive ski-snow interaction is characterised by direct force transmission and difficulty of getting the ski off its edge once the ski is carving. This behaviour has been suggested to be a main contributor to severe knee injuries in giant slalom (GS). The aim of the current study was to provide a foundation for new equipment specifications in GS by considering two perspectives: Reducing the ski's aggressiveness for injury prevention and maintaining the external attractiveness of a ski racer's technique for spectators.

Methods Three GS ski prototypes were defined based on theoretical considerations and were compared to a reference ski $\left(P_{\text {ref }}\right)$. Compared to $P_{\text {ref, }}$ all prototypes were constructed with reduced profile width and increased ski length. The construction radius (sidecut radius) of Pref was $\geq 27 \mathrm{~m}$ and was increased for the prototypes: $30 \mathrm{~m}$ $\left(P_{30}\right), 35 \mathrm{~m}\left(P_{35}\right)$, and $40 \mathrm{~m}\left(\mathrm{P}_{40}\right)$. Seven World Cup level athletes performed GS runs on each of the three prototypes and $\mathrm{P}_{\text {ref }}$. Kinetic variables related to the skisnow interaction were assessed to quantify the ski's aggressiveness. Additionally, 13 athletes evaluated their subjective perception of aggressiveness. 15 sports students rated several videotaped runs to assess external attractiveness.

Results Kinetic variables quantifying the ski's aggressiveness showed decreased values for $P_{35}$ and $P_{40}$ compared to $P_{\text {ref }}$ and $P_{30}$. Greater sidecut radius reduced subjectively perceived aggressiveness. External attractiveness was reduced for $\mathrm{P}_{40}$ only.

Conclusions This investigation revealed the following evaluation of the prototypes concerning injury prevention and external attractiveness: $P_{30}$ : no preventative gain, no loss in attractiveness; $P_{35}$ : substantial preventative gain, no significant loss in attractiveness; $\mathrm{P}_{40}$ : highest preventative gain, significant loss in attractiveness.

\section{INTRODUCTION}

Skier safety is an important matter for the International Ski Federation (FIS). Since 2006, evidence-based research on injury prevention in competitive skiing has been conducted under the guidance and support of FIS within the "FIS Injury Surveillance System". According to the sequence of prevention model by van Mechelen $e t$ al ${ }^{1}$ research projects have been conducted in the areas of epidemiology $y^{2-5}$ and injury causes. ${ }^{6-11}$ On the topic of introducing prevention measures, only one study is currently available. ${ }^{12}$ These prevention measures should be based on the aetiological factors and the mechanisms as identified within the injury causes. ${ }^{1}$
Within the classification of severe injuries, the most frequently injured body part was the knee $(62,3 \%),{ }^{3}$ with a particular focus on the rupture of the anterior cruciate ligament (ACL). ${ }^{13}$ The majority of knee injuries occur while the skier is still skiing the course (83\%). ${ }^{9}$ The main mechanism for ACL injury in World Cup alpine skiing was found to be the slip-catch mechanism where the inside edge of the outer ski abruptly catches the snow surface, forcing the outer knee into internal rotation and valgus. ${ }^{10}$ In the same study, a similar loading pattern was observed for the dynamic snow plow. Injury prevention efforts should, therefore, focus on the slip-catch mechanism and the dynamic snow plow. ${ }^{10}$

According to the perception of expert stakeholders of the World Cup ski racing community, aggressive ski behaviour is one of the main contributors to the aforementioned injury mechanism. ${ }^{6}$ Aggressive ski behaviour is characterised by a too direct force transmission between ski and snow and the phenomenon that the ski becomes difficult to get off its edge once it is carving. As a result, the athlete is unable to control the ski in the event of an out-of-balance situation because due to its selfsteering effect, the ski's behaviour becomes unpredictable. ${ }^{8}$ Consequently, it seems reasonable to assume that aggressive ski behaviour favours the 'catch of the edge' in an out-of-balance situation. ${ }^{8}$ Less aggressive skis (eg, ones with a greater turning radius), however, are theoretically associated with a decreased self-steering effect, which might affect their performance during controlled skiing (ie, not out-of-balance situations). ${ }^{14}{ }^{15}$ One could presume that less aggressive skis require a different technique to make them turn and this could potentially result in decreased attractiveness for competitors and spectators.

Therefore, the aim of this study was to provide the decision makers of FIS with an evidence-based foundation for equipment specification changes in giant slalom (GS) by verifying the achievability of the following goal: GS specific injury prevention by a reduction of the ski's aggressiveness, and maintaining the external attractiveness of ski technique to spectators.

\section{METHODS}

\section{Definition of prototypes}

In a first step, prototypes were determined, constructed and subsequently analysed. An expert group consisting of researchers, FIS Race Directors 
and representatives of the Ski Racing Suppliers Association (SRS) defined the prototypes by considering practical and existing scientific knowledge. The geometrical factors 'sidecut radius', 'ski width' and 'ski length' as well as the mechanical properties 'homogenous bending line' and 'torsional stiffness' were assumed to be the driving factors for aggressive ski behaviour. ${ }^{6}{ }^{15}$ The ski's self-steering effect was assumed to be mainly dependent on the sidecut radius and the ski's bending characteristics. ${ }^{14}$ However, not every technical solution that could potentially reduce the ski's aggressiveness was viable. Constructive and commercial considerations of SRS, as well as limitations with respect to an appropriate execution of the rules after the competition by FIS lead to certain constraints. Considering these constraints, only three basic geometric variables (length, width and sidecut radius) ${ }^{16-18}$ were altered and experimentally tested as depicted in table 1. All prototypes were constructed under the guidance of SRS, strictly adhered to by predefined geometrical variables and material composition. Four companies (Atomic, Fischer, Head, Rossignol) produced a full set of prototypes. The corresponding reference skis $\left(\mathrm{P}_{\text {ref }}\right)$ represented the competition equipment used at the time of this study. Compared to $\mathrm{P}_{\text {ref, }}$ all prototypes $\left(\mathrm{P}_{30} ; \mathrm{P}_{35} ; \mathrm{P}_{40}\right)$ had reduced profile width under the binding (ski width) and increased ski length. The sidecut radius, representing the main self-steering effect related variable, ${ }^{14}$ was increased (table 1). The increased sidecut radius in combination with reduced width under the binding results by definition in reduced profile width among the entire ski compared to $P_{\text {ref. }}$.

\section{Determination of subjectively perceived aggressive ski behaviour (experiment 1)}

Thirteen elite male alpine athletes (Europa-Cup and World-Cup level) participated in this study. To familiarise them with the prototypes, several free skiing and GS training sessions were performed prior to the experiment. After participating in a biomechanical experiment, they were asked to complete a visual analogue scale (VAS) sheet to assess the subjectively perceived aggressiveness in relation to $\mathrm{P}_{\text {ref }}$ when skiing with the prototypes (figure 1).

The ski's aggressiveness is known to manifest in different features of the ski-snow interaction. ${ }^{6}{ }^{8}$ An overall score was calculated as a mean of these three resulting features of aggressive behaviour, without directly asking for aggressiveness (mean of three VAS values). The significance of differences for the 'overall aggressiveness score' were tested with a one-way repeated measures analysis of variance(ANOVA) $\left(\mathrm{P}_{\mathrm{ref}} / \mathrm{P}_{30} / \mathrm{P}_{35} /\right.$ $\left.\mathrm{P}_{40} ; \mathrm{p}<0.05\right)$. In case of significance, post hoc testing was performed (Bonferroni). The above described statistical procedure

Table 1 Specification of the basic geometric parameters of the giant slalom skis used for the experiments

\begin{tabular}{llrrr}
\hline & P $_{\text {ref }}{ }^{{ }^{*}}$ & \multicolumn{1}{c}{$\mathbf{P}_{\mathbf{3 0}}$} & \multicolumn{1}{c}{$\mathbf{P}_{\mathbf{3 5}}$} & \multicolumn{1}{c}{$\mathbf{P}_{\mathbf{4 0}}$} \\
\hline Ski length $(\mathrm{mm})$ & $1910 \pm 7$ & 1950 & 1950 & 1950 \\
Ski width $(\mathrm{mm})$ & $67.1 \pm 0.2$ & 65 & 65 & 65 \\
Sidecut radius $(\mathrm{m})$ & $28.7 \pm 0.3$ & 30 & 35 & 40 \\
\hline
\end{tabular}

${ }^{*} P_{\text {ref }}$ represents the original racing skis of the companies that have been mandated by SRS to serve the equipment for the experiments. Therefore, there were small variations in the geometrical variables ski length, ski width and sidecut radius between the companies (Mean $\pm S D$ ). $P_{\text {ref }}$ were in accordance with the legal specification valid until Season 2011/12: Sidecut radius $\geq 27 \mathrm{~m}$; Ski length $\geq 185 \mathrm{~cm}$; Ski width $\geq 65 \mathrm{~mm}$. was further applied to the score distance (difference) of two adjacent ski geometries $\left(\mathrm{P}_{\text {ref }} \leftrightarrow \mathrm{P}_{30} / \mathrm{P}_{30} \leftrightarrow \mathrm{P}_{35} / \mathrm{P}_{35} \leftrightarrow \mathrm{P}_{40}\right)$.

\section{Biomechanical quantification of aggressive ski behaviour (experiment 2)}

Seven male World-Cup level athletes participated in this study. The athletes performed three runs with each ski on a typical GS course (18 gait, water-injected), whereby the two fastest runs were considered for analysis. The analysed section consisted of 8 gates, resulting in 16 turns per athlete and condition (total turn number $=448$ ).

The approach used to biomechanically quantify aggressive ski behaviour is based on the following considerations: Snow penetration-, shear-, and friction forces push against the running surface of an edged ski and force the ski into a traverse, which makes the skier turn. ${ }^{19}$ Specifically: the forebody of a ski generates a groove into the snow by shearing and penetrating the snow. $^{20} 21$ This results in friction at the forebody of the ski. Along with the inertia of the skier, this also results in loading at the interface of ski and skier (ie, contact area of forefoot and equipment). The deeper the reverse camber (by sidecut radius and/or edge angle), the faster the ski will turn due to the more pronounced self-steering effect ${ }^{14} 15$ and results in a more evident loading at where forces are transmitted in and between equipment and skier. Therefore, measuring ground reaction forces for quantifying aggressive ski behaviour would seem to be reasonable.

For the current study pressure insoles were used to quantify local loads between the foot and the ski boot (PEDAR; Novel; $100 \mathrm{~Hz}$ ). Based on the pressure values the following forces were calculated relative to body weight (BW) (figure 2): Total ground reaction force $\left(\mathrm{F}_{\text {tot }}\right)$, ground reaction force of the outside leg $\left(\mathrm{F}_{\text {out }}\right)$, and the $\mathrm{F}_{\text {out }}$ portion at the forefoot $\left(\mathrm{F}_{\text {outfor }}\right)$ and rearfoot $\left(\mathrm{F}_{\text {outaft }}\right)$. The pressure insoles used are known to underestimate the real force values. ${ }^{22}$ Nevertheless, for a dependent (ie, different ski's) study design with high level athletes, the applied method can be considered adequate, since it minimally impairs the athletes during movement execution and, additionally, the areas of force transmission can be depicted. Turn separation was performed based on the functional minima of $F_{\text {tot }}$ during edge change. ${ }^{23}$ Time-normalised data were subsequently divided into four phases based on previously reported kinematic data in GS: 0-23\% Initiation; 23-52\% COM Direction Change I; 52-82\% COM Direction Change II; $82-100 \%$ Completion. ${ }^{12}{ }^{24}$ Parameter calculation and post-processing were performed using MATLAB R2012b (MathWorks).

For each athlete and condition, average curves were calculated. Based on these individual average curves, group mean values along the overall turn pathway were calculated and graphically visualised as average curve $\pm \mathrm{SE}$. The mean values of the specific turn phases were reported as mean $\pm S D$ and were tested for significant differences $(p<0.05)$. For each turn phase, repeated measures multivariate ANOVA (MANOVA) (dependent $\mathrm{F}_{\text {tot }} / \mathrm{F}_{\text {out }} / \mathrm{F}_{\text {outfor }} / \mathrm{F}_{\text {outaft }}$ independent $\left.\mathrm{P}_{\text {ref }} / \mathrm{P}_{30} / \mathrm{P}_{35} / \mathrm{P}_{40}\right)$ were calculated. In case of global significance, a one-way repeated measures ANOVA $\left(\mathrm{P}_{\mathrm{ref}} / \mathrm{P}_{30} / \mathrm{P}_{35} / \mathrm{P}_{40}\right)$ was performed on each variable, including post hoc testing with Bonferroni correction. Furthermore, ANOVA with post hoc testing was applied on the distance (difference) of two adjacent ski geometries $\left(\mathrm{P}_{\text {ref }} \leftrightarrow \mathrm{P}_{30} /\right.$ $\left.\mathrm{P}_{30} \leftrightarrow \mathrm{P}_{35} / \mathrm{P}_{35} \leftrightarrow \mathrm{P}_{40}\right)$.

To determine the degree of representativeness of the experimental setup to World Cup conditions, speed was measured for one skier (skiing with $\mathrm{P}_{\text {ref }}$ ) using dynamic dGNSS and course setting was characterised using static dGNSS. ${ }^{25}$ Median ( \pm IRQ) 
Figure 1 Visual analogue scale (VAS) to assess perceived equipment aggressiveness.

Judge the Prototypes $\left(X_{30}, \square P_{35}, \bigcirc P_{40}\right)$ relative to the

Reference Ski $\left(P_{\text {ref }}\right)$ for the following three items:

directness in force transmission

much less

$P_{\text {ref }}$

much more

forgiving ski behavior and controllability

much less

$\longmapsto P_{\text {re }}^{+}$

In case of out-of-balance situation

self dynamic behaviour, unpredictability

much less

much more

gate distance $(25.44 \pm 0.81 \mathrm{~m})$ and median horizontal gate distance $(7.13 \pm 1.16 \mathrm{~m})$ were slightly shorter than in average GS World Cup course settings $(26.24 \pm 2.25 \mathrm{~m}$ and $7.47 \pm 2.93 \mathrm{~m}$, respectively). ${ }^{26}$ Median terrain inclination $\left(-23.3^{\circ} \pm 1.9^{\circ}\right)$ was a bit steeper compared to GS World Cup races $\left(-17.8^{\circ} \pm 7.0^{\circ}\right) .^{26}$ Median skier speed $\left(18.0^{\circ} \pm 1.2 \mathrm{~m} / \mathrm{s}\right)$ was close to GS World Cup racing $(17.75 \pm 2.3 \mathrm{~m} / \mathrm{s}) .^{7} 26$

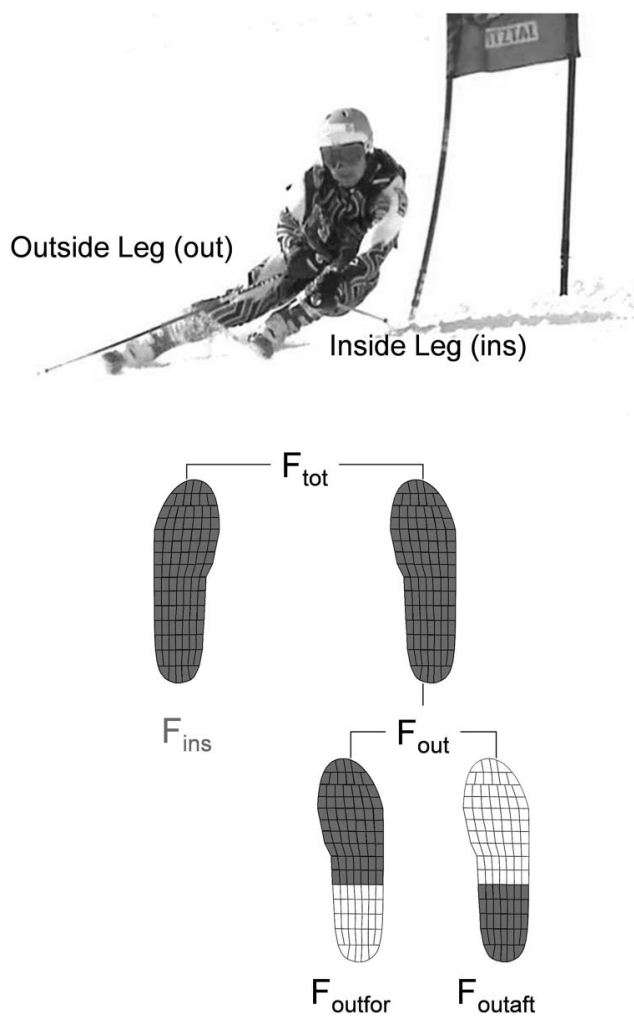

Figure 2 Top: Athlete performing a turn to the left during the experiment. In this case, the right leg represents the 'Outside Leg' (out) and the left leg the 'Inside Leg' (ins). Bottom: Sensor definition for calculating the selected ground reaction force parameters $\rightarrow$ Total $\left(\mathrm{F}_{\text {tot }}\right)$; Outside Leg $\left(\mathrm{F}_{\text {out }}\right)$; portion of $\mathrm{F}_{\text {out }}$ at the forefoot $\left(\mathrm{F}_{\text {outfor }}\right)$; portion of $\mathrm{F}_{\text {out }}$ at the rearfoot $\left(\mathrm{F}_{\text {outaft }}\right)$.

\section{Determination of external attractiveness (experiment 3)}

Twenty sports students regularly following GS events on TV participated in this study. A set of 28 videos conducted during the biomechanical experiment; 5 gate section; $\mathrm{n}=7 \times\left(\mathrm{P}_{\text {ref }}+\right.$ $\left.\mathrm{P}_{30}+\mathrm{P}_{35}+\mathrm{P}_{40}\right)$ were presented to the participants several times: Session 1 and Session 2 were used to prime the participants with respect to the spectrum of the 28 videos. During Session 3 and Session4, participants rated the randomised video via VAS (figure 3). Each video was presented three times (original speed; reduced speed; original speed) with a subsequent rating period of $15 \mathrm{~s}$. Within Session 3 and Session 4, a break of 5 min was permitted, and between the sessions a break of 15 min was given.

To evaluate the rater reliability of participants, individual correlations on the 28 VAS values between Session 3 and Session 4 were calculated, which resulted in the exclusion of five participants with $r<0.7$. The VAS values from the remaining 15 participants were finally tested for statistical differences (Session3). The significance of the VAS value on external attractiveness was tested with a two-way repeated measures ANOVA (4 ( $\mathrm{P}_{\text {ref }} / \mathrm{P}_{30} /$ $\left.\mathrm{P}_{35} / \mathrm{P}_{40}\right) \times 7$ (athletes); $\mathrm{p}<0.05$ ) including post hoc analysis with Bonferroni correction.

\section{RESULTS}

\section{Determination of subjectively perceived aggressive ski} behaviour (experiment1)

The ANOVA and all pairwise comparisons revealed significant differences in the overall aggressiveness scores (figure 4). The VAS scores decreased with greater sidecut radius $\left(\right.$ Pref $\left.>P_{30}>P_{35}>P_{40}\right)$. The perceived aggressiveness decreased almost linearly with sidecut radius increase, so the score distances between two adjacent ski geometries did not reveal significant differences $\left(p>0.175 ; \eta_{p}^{2}=0.272\right)$.

\section{Biomechanical quantification of aggressive ski behaviour (experiment 2)}

The time-courses of ground reaction force for the four ski sample are presented in figure 5. Generally, all ground reaction force parameters decreased with greater sidecut radius, especially in the phases after gate passage. This observation is supported by the MANOVA results for the specific turn phases: no 
Figure 3 Visual analogue scale (VAS) to assess external attractiveness.

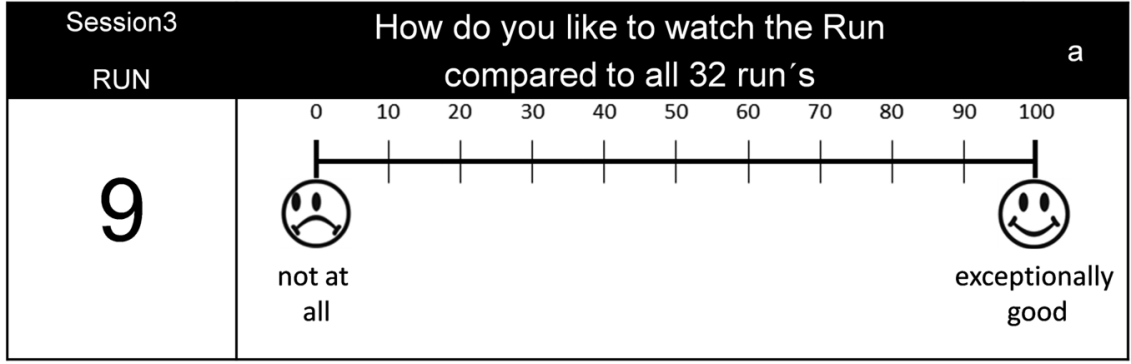

significance for Initiation $\left(\mathrm{p}<0.225, \eta_{\mathrm{p}}^{2}=0.201\right)$ and $C O M$ Direction Change I $\left(\mathrm{p}<0.078, \eta_{\mathrm{p}}^{2}=0.245\right)$; but significance for COM Direction Change II $\left(\mathrm{p}<0.022, \eta_{\mathrm{p}}^{2}=0.331\right)$; and Completion $\left(\mathrm{p}<0.014, \eta_{\mathrm{p}}^{2}=0.349\right)$.

During COM Direction Change II the subsequent ANOVÀs revealed significant differences for $\mathrm{F}_{\text {tot }}, \mathrm{F}_{\text {out }}$ and $\mathrm{F}_{\text {outfore, }}$ but not for $\mathrm{F}_{\text {outaft }}$ (table 2). Post hoc comparison did not reveal significant differences between $\mathrm{P}_{\text {ref }}$ and $\mathrm{P}_{30}$ and between $\mathrm{P}_{35}$ and $\mathrm{P}_{40}$ for any parameter. From all other pairwise comparisons, greatest differences were observed for $\mathrm{F}_{\text {outfore }}$ (from $-11.2 \%$ up to $-17.2 \%$; table 2). For this parameter, the distances of two adjacent ski geometries also were significant $(p<0.028, \eta=0.831)$ : $\mathrm{P}_{\text {ref }} \leftrightarrow \mathrm{P}_{30} \quad(0.02 \mathrm{BW} \pm 0.04)$ is significantly smaller $\quad(\mathrm{p}<0.042)$ compared to $\mathrm{P}_{30} \leftrightarrow \mathrm{P}_{35}(0.11 \mathrm{BW} \pm 0.04) ; \mathrm{P}_{30} \leftrightarrow \mathrm{P}_{35}$ is significantly greater $(\mathrm{p}<0.048)$ compared to $\mathrm{P}_{35} \leftrightarrow \mathrm{P}_{40}(0.03 \mathrm{BW} \pm 0.02)$; no significant difference between $\mathrm{P}_{\text {ref }} \leftrightarrow \mathrm{P}_{30}$ and $\mathrm{P}_{35} \leftrightarrow \mathrm{P}_{40}$.

\section{Determination of external attractiveness (experiment 3)}

The two-way ANOVA and some of the post hoc analyses revealed significant differences for external attractiveness (figure 6). For the factor ski, no differences were found for $\mathrm{P}_{\text {ref, }}$, $\mathrm{P}_{30}$ and $\mathrm{P}_{35} . \mathrm{P}_{40}$, however, was significantly less attractive compared to all other skis.

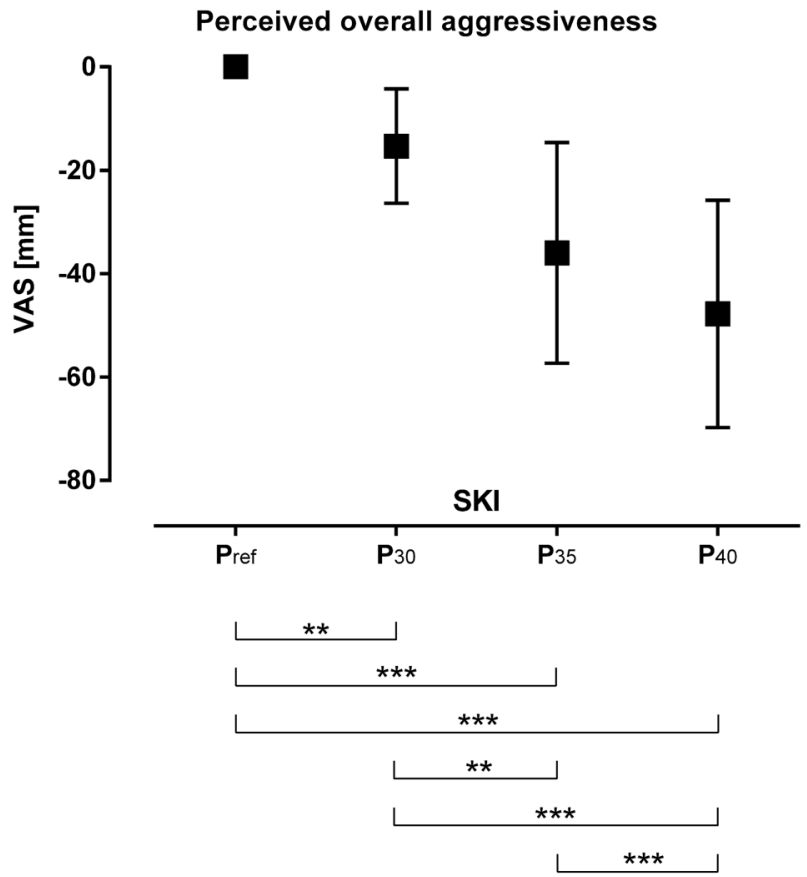

Figure 4 Mean \pm SD of the perceived aggressiveness for the four ski conditions $(n=13)$. The negative value represents a decrease in aggressiveness score compared to $P_{\text {ref. }}$. Bars across indicate significant differences $\left({ }^{*} p<0.05,{ }^{* *} p<0.01,{ }^{* *} p<0.001\right)$.

\section{DISCUSSION}

The main findings of this study were: (1) a combination of small alterations in ski length, ski width and sidecut radius $\left(\mathrm{P}_{\text {ref }} \mathrm{vs}\right.$ $\mathrm{P}_{30}$ ) was found to lead to an altered perception of the ski's aggressiveness, but not to a significant decrease in the biomechanically quantified aggressiveness; (2) a substantially greater sidecut radius $(35 \mathrm{~m}$ and $40 \mathrm{~m})$ led to a decrease in the perception of the ski's aggressiveness accompanied by a reduction of ground reaction force after gate passage, particularly under the forefoot of the outside leg; (3) the forces acting under the forefoot did not decrease linearly with greater sidecut radius $\left(\mathrm{P}_{30} \leftrightarrow \mathrm{P}_{35}>\mathrm{P}_{35} \leftrightarrow \mathrm{P}_{40}\right)$; (4) external attractiveness was significantly decreased only when skiing with $\mathrm{P}_{40}$.

\section{Quantifying an aggressive ski behaviour}

The sidecut radius is one of the most important variables of ski geometry because it largely determines how a ski turns. ${ }^{15} 27$ To some extent, this was verified by this study as well, since the intervention according to ski width and ski length $\left(\mathrm{P}_{30}\right)$ did not reveal significant differences with respect to the biomechanical measures compared to $P_{\text {ref. }}$.

As a ski is tipped up on its edge and pressed against the snow surface, the sidecut radius allows the ski into a reverse camber position and makes the ski turn as it moves forward. This is called the ski's self-steering effect. ${ }^{14}$ In the context of injury mechanisms, this behaviour is also of interest. By catching the inside edge in an out-of-balance situation, a carving ski rotates inward and can produce an internal tibial torque, which was identified as 'aggressive ski behaviour'. ${ }^{11}$ In other words, the functionally positive associated term 'self-steering effect' while controlled skiing, ${ }^{14} 152829$ becomes negatively associated in the case of out-of-balance situations and is then called 'aggressive ski behaviour'. ${ }^{8-10}$ Strictly speaking, this study explored the self-steering effect of different ski geometries in controlled skiing situations. The ski's aggressiveness, therefore, was only indirectly explored. It has to be mentioned, that an assessment of aggressiveness in out-of-balance situations is experimentally difficult to perform and ethically not justifiable since it would consciously force the athlete into a risk position of severe injury.

As described from a mechanical perspective in the methods, $\mathrm{F}_{\text {outfore }}$ seems to be a reasonable measure of the self-steering effect and, therefore, an estimate of aggressive ski behaviour. The decrease in $F_{\text {outfore }}$ with greater sidecut radius supports the argument above: while skiing with greater sidecut radius, the self-steering effect is less pronounced and consequently the forebody of the ski does penetrate and shear the snow less. Thus, the resulting effect of inertia in the direction of travel is reduced, the outcome of which is lower forces under the forefoot. ${ }^{14}{ }^{15-21}$ The advantage of this approach compared to the rating of perceived aggressiveness is obvious: results are subjectively unbiased and the parameter seems to be more sensitive to the evaluation of subtle differences, since differences between 

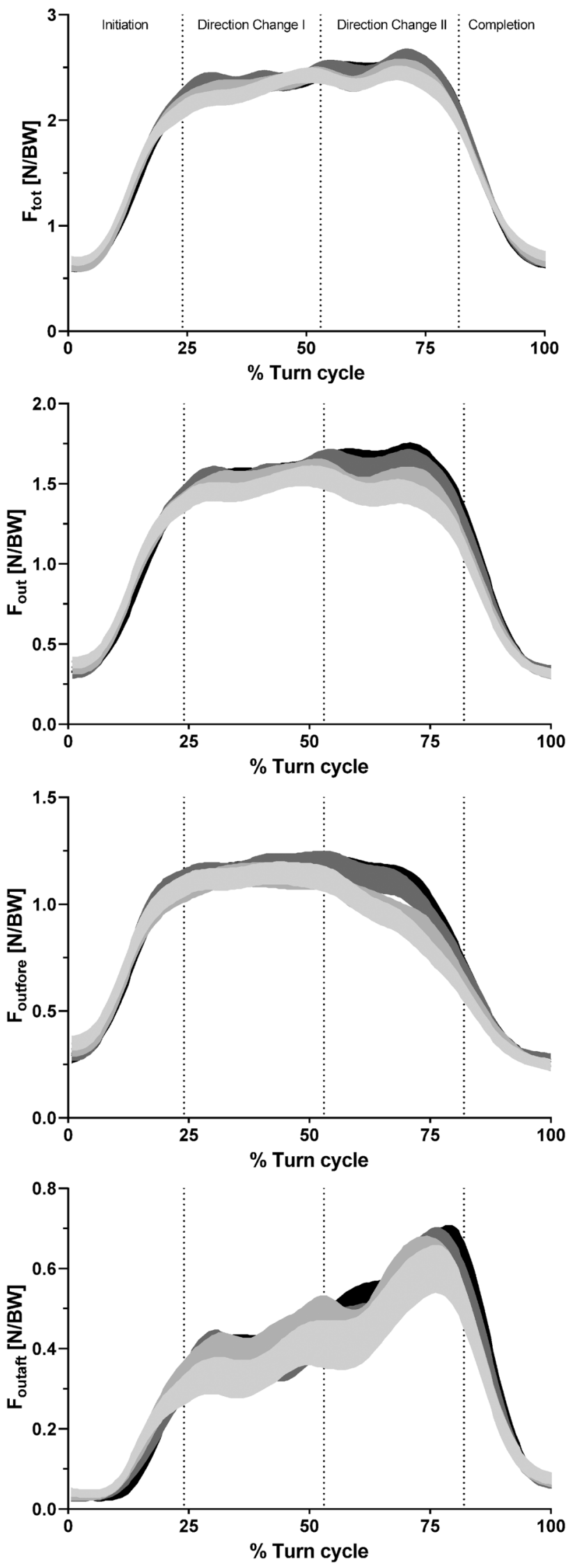

Figure 5 Areas of uncertainty around the estimate of the mean $( \pm S E)$ illustrating the occurring ground reaction forces $\left(\mathrm{F}_{\text {tot }}, \mathrm{F}_{\text {out }}, \mathrm{F}_{\text {outfor }}\right.$ and $F_{\text {outaft }}$ defined in figure 2) over one turn cycle $(n=7)$; from black to light grey correspond to the following skis: black $\triangleq \mathrm{P}_{\text {ref }} \rightarrow \mathrm{P}_{30} \rightarrow \mathrm{P}_{35} \rightarrow \mathrm{P}_{40}$ $\stackrel{\wedge}{=}$ light grey. Vertical dotted lines separate the specific turn phases. the distances of the skis used also were identified $\left(\mathrm{P}_{\text {ref }} \leftrightarrow \mathrm{P}_{30}<\mathrm{P}_{30} \leftrightarrow \mathrm{P}_{35}>\mathrm{P}_{35} \leftrightarrow \mathrm{P}_{40}\right)$, which was not the case for perception.

Theoretical approaches usually neglect the possibility of intuitively distributing the load on both the inside and outside leg. ${ }^{15} 2730$ Although the inside leg loading obtained attention in connection with steering a ski with small sidecut radius, ${ }^{29}$ the outside leg is still mainly responsible for steering. The inside leg is used primarily to support the outside leg; for instance, to avoid falling too far to the inside if the direction of the resultant forces do not match whole body inclination. ${ }^{14}$ Hence, it is plausible to observe the main differences of the self-steering effect on the outside leg. In the current study the greatest differences were observed with respect to this phenomenon (significant for $\mathrm{F}_{\text {out }}$ and $\mathrm{F}_{\text {outfore }}$ ).

Interestingly, the theoretical considerations for skiing pure carved turns match best with the phase of COM Direction Change II. ${ }^{15} 2730$ Several theoretical approaches-always presuming pure carving without skidding-demonstrated that greater sidecut radius leads to decreased ground reaction force. Once a skier passes the fall line (the beginning of COM Direction Change II), the edge angles typically increase, ${ }^{14}$ and lean angles reach the highest values. ${ }^{12}$ During this phase, skid angle, as well as turn radius, usually show the lowest values resulting in high amounts of carving. ${ }^{21} 31$ This explains the most pronounced differences observed in this study for that phase and seems to be an adequate model for investigating the self-steering effect, and consequently, for investigating the aggressiveness of various skis. From an injury prevention point of view, this phase is also of particular interest because more than half of the ACL-injuries occur while turning, mainly during the steering phase out of the fall line. ${ }^{10}$

\section{Ski geometry as an injury prevention measure}

An earlier study comparing the most extreme horizontal gate distances in GS concluded that as long as the course setting changes were not substantial enough, injury risk might not be reduced considerably, since athletes are still able to adapt and partly compensate by changing their timing strategy. ${ }^{12}$ In contrast, more substantial changes might leave the borders of usual technical solutions and athletes would have to adapt their skiing technique substantially. The adapted technical solutions could potentially be less attractive for the spectators. Therefore, to minimise injury risk while maintaining attractiveness are challenges for decision-makers and must be considered carefully.

To our knowledge, the strategy of assessing both aspects prior to introducing the prevention measure is unique and was performed for the first time in alpine ski racing by the current study. Our results revealed that potential gains in injury prevention and the beginning of a loss of attractiveness occur on different levels of intervention: from a prevention perspective, a sidecut radius of $35 \mathrm{~m}$ provides substantial gain (highest distance between $\mathrm{P}_{30}$ and $\mathrm{P}_{35}$ ); from an attractiveness perspective, a significant loss was observed only for a $40 \mathrm{~m}$ sidecut radius accompanied with moderate additional reduction of injury risk compared to $\mathrm{P}_{35}$. This difference is important for the decisionmakers of FIS in terms of balancing performance and injury related arguments against each other.

For decades, as the governing body of international ski competition, FIS has set limits on different geometrical parameters of racing skis by citing injury prevention concerns. Despite the sustained efforts (eg, revised specifications 2003 and 2007), ${ }^{16} 32$ injury rates were reported to be alarmingly high for six consecutive seasons (2006-2012). ${ }^{2}$ Earlier revisions of the equipment 
Table 2 Descriptive and inferential statistics of the average ground reaction forces $\left(\mathrm{F}_{\text {tot }}, \mathrm{F}_{\text {out }}, \mathrm{F}_{\text {outfore }}\right.$ and $\mathrm{F}_{\text {outaft }}$ in N/BW) in COM Direction Change // for the tested skis $\left(\mathrm{P}_{\text {ref, }}, \mathrm{P}_{30}, \mathrm{P}_{35}, \mathrm{P}_{40}\right)$

\begin{tabular}{|c|c|c|c|c|c|c|c|c|c|c|c|c|}
\hline & \multicolumn{4}{|l|}{ Mean \pm SD } & \multicolumn{2}{|l|}{ ANOVA* } & \multicolumn{6}{|c|}{ Pairwise comparisons } \\
\hline & $P_{\text {ref }}$ & $P_{30}$ & $P_{35}$ & $P_{40}$ & $\mathrm{p}$ Value & $\eta_{p}^{2}$ & $P_{\text {ref }} / P_{30}$ & $P_{\text {ref }} / P_{35}$ & $P_{\text {ref }} / P_{40}$ & $\mathbf{P}_{30} / \mathbf{P}_{35}$ & $\mathbf{P}_{30} / \mathbf{P}_{40}$ & $\mathrm{P}_{35} / \mathrm{P}_{40}$ \\
\hline $\mathrm{F}_{\text {tot }}(\mathrm{N} / \mathrm{BW})$ & $2.44 \pm 0.18$ & $2.44 \pm 0.23$ & $2.36 \pm 0.21$ & $2.32 \pm 0.22$ & $0.002^{* *}$ & 0.622 & & & $-4.8 \%^{(\mathrm{t})}$ & $-3.6 \%^{(\mathrm{t})}$ & $-5.1 \%^{(\mathrm{t})}$ & \\
\hline $\mathrm{F}_{\text {out }}(\mathrm{N} / \mathrm{BW})$ & $1.61 \pm 0.14$ & $1.58 \pm 0.13$ & $1.47 \pm 0.16$ & $1.41 \pm 0.11$ & $0.000^{* * *}$ & 0.797 & & $-9.5 \%$ ** & $-14.5 \%$ ** & $-7.1 \%^{(\mathrm{t})}$ & $-12.1 \%$ ** & $-4.6 \%{ }^{\left({ }^{(t)}\right.}$ \\
\hline $\mathrm{F}_{\text {outfore }}(\mathrm{N} / \mathrm{BW})$ & $1.06 \pm 0.20$ & $1.04 \pm 0.24$ & $0.94 \pm 0.24$ & $0.90 \pm 0.22$ & $0.000^{* * *}$ & 0.826 & & $-13.0 \%$ ** & $-17.2 \% *$ & $-11.3 \%$ ** & $-15.4 \% *$ & \\
\hline $\mathrm{F}_{\text {outaft }}(\mathrm{N} / \mathrm{BW})$ & $0.55 \pm 0.19$ & $0.53 \pm 0.23$ & $0.53 \pm 0.27$ & $0.50 \pm 0.20$ & $0.511^{\mathrm{ns}}$ & 0.133 & & & & & & \\
\hline
\end{tabular}

Level of significance: ${ }^{(t)} p<0.10,{ }^{*} p<0.05,{ }^{* *} p<0.01,{ }^{* * *} p<0.001$. ANOVA results are based on the Greenhouse-Geisser correction. Post hoc method with Bonferroni correction for pairwise comparison.

*Prior the ANOVA test a global significance was identified (MANOVA: $p<0.022, \eta_{p}^{2}=0.331$ ). ANOVA, analysis of variance; MANOVA, multivariate ANOVA

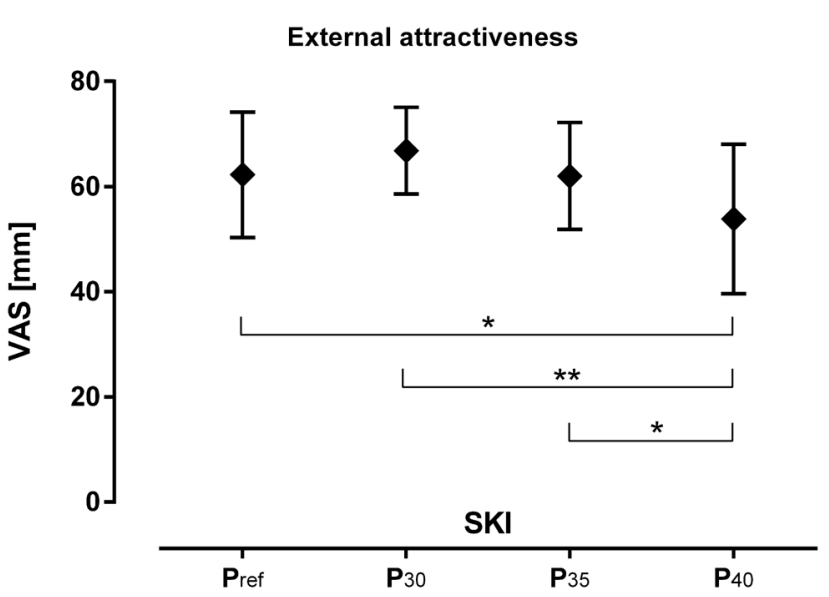

Figure 6 Mean $\pm S D$ of the external attractiveness values for the four ski conditions $(n=15)$. Bars across indicate significant differences $\left({ }^{*} p<0.05,{ }^{* *} p<0.01,{ }^{* *} p<0.001\right)$.

specifications were only based on discussions within key stakeholders of the skiing community. In the current study a target-oriented prevention measure-based on previous research in the area of epidemiology, internal risk factors and mechanisms $-{ }^{2-11}$ was evaluated with respect to intervention magnitude and influence on attractiveness. In this context, a key strength of this study was that the outcome provided substantial new data on an evidence based level, which were considered from FIS for the latest amendments of their equipment specifications. ${ }^{18}$

\section{CONCLUSION}

This study explored the aggressiveness of different ski geometries while skiing a typical GS course. An 'aggressive' ski behaviour in out-of-balance situations is associated with a direct force transmission at the ski-snow interaction and is known to be a main risk factor for severe knee injuries in GS. The ground reaction forces under the forefoot of the outside leg seem to be an innovative and reasonable measure to quantify the aggressiveness of skis. Compared to assessing the athletes' perceptions, the aforementioned measure is more subtle and free of subjective bias.

Furthermore, data from this study showed that potential gains in injury prevention by reducing the ski's self-dynamic effect (aggressive ski behaviour in an out-of-balance situation) and the beginning of the loss of attractiveness for the spectator occur on a different level of intervention. Consequently, for the decisionmakers of FIS this investigation suggested three evidence-based arguments: (1) $\mathrm{P}_{30}$ : no preventative gain, no loss in attractiveness; (2) $\mathrm{P}_{35}$ : substantial preventative gain, no significant loss in attractiveness; (3) $\mathrm{P}_{40}$ : highest preventative gain, significant loss in attractiveness.

\section{What are the new findings}

- This is the first study in alpine skiing assessing preventative gain in combination with external attractiveness prior to introducing the prevention measure.

- An injury prevention approach, which is discipline-specific and addresses injury specific risk factors.

\section{How might it impact on clinical practice in the future?}

- Decreased ski aggressiveness can be quantified by calculating ground reaction forces under the forefoot of the outside leg free of subjective bias and with greater resolution than based on subjectively perceived rating.

- Moderate adjustment of ski with ski length and sidecut radius has no impact on specific risk factors; but a more pronounced increase in sidecut radius does have a positive impact.

- Potential gains in injury prevention and the beginning of the loss of attractiveness occur on a different level of intervention, which is important to know for adequately revising FIS competition rules
Acknowledgements The authors would like to thank Rüdiger Jahnel, Peter Scheiber, Christoph Eiter and Atle Skaardal for their on-hill support and SRS for organising the prototype production and athlete recruitment.

Contributors JK, JS and EM conceptualised the study design. JK organised and coordinated the biomechanical field study. JK, JS, MG contributed to the data collection. JK, supported by JS and MG conducted the data processing and analysis. All authors contributed the intellectual content of the study, manuscript writing and approved the final version of this article.

Funding This study was financially supported by the International Ski Federation (FIS).

Competing interests None declared.

Ethics approval This study was approved by the Ethics Committee of the Department of Sport Science and Kinesiology at the University of Salzburg.

Provenance and peer review Not commissioned; externally peer reviewed.

Open Access This is an Open Access article distributed in accordance with the Creative Commons Attribution Non Commercial (CC BY-NC 4.0) license, which permits others to distribute, remix, adapt, build upon this work non-commercially, and license their derivative works on different terms, provided the original work is properly cited and the use is non-commercial. See: http://creativecommons.org/ licenses/by-nc/4.0/ 


\section{REFERENCES}

1 van Mechelen W, Hlobil H, Kemper HC. Incidence, severity, etiology and prevention of sports injuries. A review of concepts. Sports Med 1992;14:82-99.

2 Bere T, Flørenes TW, Nordsletten L, et al. Sex differences in the risk of injury in World Cup alpine skiers: a 6-year cohort study. Br J Sports Med 2014;48:36-40.

3 Flørenes TW, Bere T, Nordsletten L, et al. Injuries among male and female World Cup alpine skiers. Br J Sports Med 2009;43:973-8.

4 Flørenes TW, Nordsletten L, Heir S, et al. Recording injuries among World Cup skiers and snowboarders: a methodological study. Scand J Med Sci Sports 2011;21:196-205.

5 Flørenes TW, Nordsletten L, Heir S, et al. Injuries among World Cup ski and snowboard athletes. Scand J Med Sci Sports 2012;22:58-66.

6 Spörri J, Kröll J, Amesberger G, et al. Perceived key injury risk factors in world cup alpine ski racing-an explorative qualitative study with expert stakeholders. $\mathrm{Br} \mathrm{J}$ Sports Med 2012;46:1059-64.

7 Gilgien M, Spörri J, Kröll J, et al. Mechanics of turning and jumping and skier speed are associated with injury risk in men's World Cup alpine skiing: a comparison between the competition disciplines. Br J Sports Med 2014;48:742-7.

8 Bere T, Flørenes TW, Krosshaug T, et al. Events leading to anterior cruciate ligament injury in World Cup Alpine Skiing: a systematic video analysis of 20 cases. Br J Sports Med 2011;45:1294-302.

9 Bere T, Flørenes TW, Krosshaug T, et al. A systematic video analysis of 69 injury cases in World Cup alpine skiing. Scand J Med Sci Sports 2014;24:667-77.

10 Bere T, Flørenes TW, Krosshaug T, et al. Mechanisms of anterior cruciate ligament injury in World Cup alpine skiing: a systematic video analysis of 20 cases. Am J Sports Med 2011;39:1421-9.

11 Bere T, Mok KM, Koga $\mathrm{H}$, et al. Kinematics of anterior cruciate ligament ruptures in World Cup alpine skiing: 2 case reports of the slip-catch mechanism. Am J Sports Med 2013;41:1067-73

12 Spörri J, Kröll J, Schwameder $\mathrm{H}$, et al. Course setting and selected biomechanical variables related to injury risk in alpine ski racing: an explorative case study. $\mathrm{Br} J$ Sports Med 2012;46:1072-7.

13 Pujol N, Blanchi MP, Chambat P. The incidence of anterior cruciate ligament injuries among competitive alpine skiers: a 25-year investigation. Am J Sports Med 2007;35:1070-4.

14 LeMaster R. Ultimate skiing. Leeds, UK: Human Kinetics, 2010:212.

15 Howe J. The new skiing mechanics. 2nd edn. Waterford: McIntire Publishing, 2001.

16 International Ski Federation FIS. Specification for competition equipment and comercial markings. Edition 2007/08 ed. Oberhofen, Switzerland: Self-publisher, 2007.

17 International Ski Federation FIS. Specification for competition equipment and comercial markings. Edition 2011/12 ed. Oberhofen, Switzerland: Self-publisher, 2011.
18 International Ski Federation FIS. Specification for competition equipment and comercial markings. Edition 2012/13 ed. Oberhofen, Switzerland: Self-publisher, 2012.

19 Mössner M, Heinrich D, Schindelwig K, et al. Modeling the ski-snow contact in skiing turns using a hypoplastic vs an elastic force-penetration relation. Scand J Med Sci Sports 2014;24:577-85.

20 Lieu DK, Mote CD. Mechanics of the turning snow ski. In: Johnson RJ, Mote CD, eds. Skiing trauma and safety: fifth international symposium. Philadelphia: PA: American Society for Testing and Materials, 1985:117-40.

21 Reid R. A Kinematic and Kinetic Study of Alpine Skiing Technique in Slalom (PhD Thesis). Dissertation, ISBN Nr. 978-82-502-0440-9. Oslo: Norwegian School of Sport Sciences, 2010.

22 Nakazato K, Scheiber P, Müller E. A comparison of ground reaction forces determined by portable force-plate and pressure-insole systems in alpine skiing. J Sport Sci Med 2011;10:754-62.

23 Spörri J, Kröll J, Haid C, et al. Potential Mechanisms Leading to Overuse Injuries of the Back in Alpine Ski Racing: a Descriptive Biomechanical Study. Am J Sports Med 2015;43:2042-8.

24 Spörri J, Kröll J, Schwameder $\mathrm{H}$, et al. Turn characteristics of a top world class athlete in giant slalom - a case study assessing current performance prediction concepts. Int J Sport Sci Coach 2012;7:647-59.

25 Gilgien M, Spörri J, Limpach P, et al. The effect of different Global Navigation Satellite System methods on positioning accuracy in elite alpine skiing. Sensors (Basel) 2014;14:18433-53.

26 Gilgien M, Crivelli P, Spörri J, et al. Correction: characterization of course and terrain and their effect on skier speed in world cup alpine ski racing. PLOS ONE 2015; 10:e0128899.

27 Mössner M, Nachbauer W, Schindelwig K. [Effect of ski tapering on turning radius and stress]. Sportverletz Sportschaden 1997;11:140-5.

28 Federolf $\mathrm{P}$, Aurer $\mathrm{M}$, Fauve $\mathrm{M}$, et al. Subjective Evaluation of the Performance of Alpine Skis and Correlations MechanicaL Ski Properties. Eng Sport 2006;6:287-92.

29 Müller $\mathrm{E}$, Schwameder $\mathrm{H}$. Biomechanical aspects of new techniques in alpine skiing and ski-jumping. J Sports Sci 2003;21:679-92.

30 Niessen W, Müller E. Carving-biomechanische Aspekte bei der Verwendung stark taillierter Skier und erhöhter Standflächen im alpinen Skisport. Leistungssport 1999;1:39-44.

31 Spörri J, Kröll J, Schiefermüller C, et al. Line characteristics and performance in giant slalom. In: Müller $\mathrm{E}$, Lindinger $\mathrm{S}$, Stöggl $\mathrm{T}$, et al. eds. 5th int. congress on science and skiing; 14.-19. December 2012; Austria: St.Christoph, 2010:57.

32 International Ski Federation FIS. Specification for competition equipment and comercial markings. Edition 2003/04 ed. Oberhofen, Switzerland: Self-publisher, 2003. 